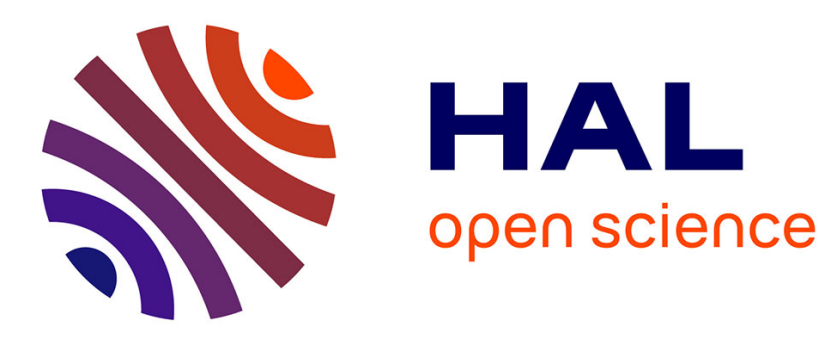

\title{
On the micromodelling of dynamic response for thermoelastic periodic composites
}

\author{
Czeslaw Wozniak, Margaret Wozniak
}

\section{To cite this version:}

Czeslaw Wozniak, Margaret Wozniak. On the micromodelling of dynamic response for thermoelastic periodic composites. Proceedings of the IUTAM Symposium held in Aalborg, Denmark, 22-25 August 1994, Aug 1994, Aalborg, Denmark. pp.387-395. hal-00944527

\section{HAL Id: hal-00944527 \\ https://hal.science/hal-00944527}

Submitted on 18 Feb 2014

HAL is a multi-disciplinary open access archive for the deposit and dissemination of scientific research documents, whether they are published or not. The documents may come from teaching and research institutions in France or abroad, or from public or private research centers.
L'archive ouverte pluridisciplinaire HAL, est destinée au dépôt et à la diffusion de documents scientifiques de niveau recherche, publiés ou non, émanant des établissements d'enseignement et de recherche français ou étrangers, des laboratoires publics ou privés. 


\title{
ON THE MICROMODELLING OF DYNAMIC RESPONSE FOR THERMOELASTIC PERIODIC COMPOSITES
}

\author{
CZ. WOŹNIAK \\ Institute of Fundamental Technological Research \\ Świętokrzyska 21, PL 00-049 Warszawa, Poland \\ M. WOŹNIAK (Ms.) \\ Technical University of Lódz, Department of Geotechnical and Structure \\ Engineering \\ Al. Politechniki 6, PL 93-590 Lódż, Poland
}

\section{Introduction}

As it is known, the asymptotic homogenization methods for micro-periodic composites, leading to the effective modulus theories, neglect inertial aspects of microstructural features related to the size of constituents (cf. $[1,2]$ and the references therein). The main aim of this contribution is to propose a new approach to the formulation of macro-models for micro-periodic thermoelastic composite materials. This approach takes into account a length-scale effect on a dynamic response of a composite and is simple enough to be applied in analysis of engineering problems and for quasi-stationary processes reduces to the special effective modulus theory, [3,4]. Theories of this type for elastic composite materials and structures were discussed in [5-7] and are termed refined macro-theories. In this paper governing equations of the refined macro-thermoelastodynamics are formulated on the basis of heuristic hypotheses concerning the expected form of disturbances in displacement and temperature fields, caused by the micro-inhomogeneity of a composite. At the same time a special form of macro-modelling approximations is used. The resulting equations are obtained without any 
reference to a boundary value problem on the representative volume element, that is required in asymptotic homogenization approaches, $[1,2]$. The general considerations are illustrated by the simple example the aim of which is to compare results of the refined macro-theory and those of the effective modulus theory. It is shown that the microstructure length scale effects, described by the proposed macro-theory, play an essential role in investigations of the non-stationary behaviour of the composites.

The analysis will be carried out in the framework of the linear thermoelastodynamics under assumption of the perfect bonding between constituents of the composite. The considerations are restricted to micro-periodic bodies, i.e., the maximum length dimension of the representative volume element is sufficiently small compared to the minimum characteristic length dimension of the body.

Denotations. The region in the reference space, occupied by the undeformed composite body, will be denoted by $\Omega$. By $x \equiv\left(x_{1}, x_{2}, x_{3}\right)$ and $\tau$ we denote points of $\Omega$ and a time coordinate, respectively, and $x_{1}, x_{2}, x_{3}$ are Cartesian orthogonal coordinates in the reference space. Subscripts $i, j, k, 1$ related to these coordinates nun over the sequence 1 , 2,3 . Superscripts $a, b$, run over $1, \ldots, n$ being related to a certain micro-discretization of the representative volume element $\mathrm{V}=\left(0, l_{1}\right) \times\left(0, l_{2}\right) \times\left(0, l_{3}\right)$ of the periodic composite structure. The summation convention holds both for i, j, k, 1 and a, b. For any $V$-periodic integrable function $f(x)$ we introduce the averaging operator

$$
\langle f\rangle \equiv \frac{1}{l_{1} l_{2} l_{3}} \int_{V} f(x) d v,
$$

where $\mathrm{dv}=\mathrm{dx} \mathrm{dx}_{2} \mathrm{dx}_{3}$. The area element of the boundary $\partial \Omega$ will be denoted by da. The remaining basic denotations will be given at the beginning of the subsequent section. 


\section{Analysis}

\subsection{FOUNDATIONS}

Foundations of the proposed approach are based on the governing equations of thermo-elastodynamics. Denoting by $\mathrm{u}_{\mathrm{i}}, \theta, \mathrm{s}_{\mathrm{ij}}, \mathrm{q}_{\mathrm{i}}, \rho, \varepsilon, \mathrm{b}_{\mathrm{i}}, \alpha, \mathrm{s}_{\mathrm{i}}$, q displacements, temperature, stresses, heat fluxes, mass density, specific energy, body forces, heat supply, boundary tractions and boundary heat supply, respectively, we shall postulate the principle of balance of momentum and that of balance of energy in the following weak form

$$
\begin{aligned}
& \frac{d}{d \tau} \int_{\Omega} \rho(\mathbf{x}) \dot{u}_{i}(\mathbf{x}, \tau) \delta u_{i}(\mathbf{x}) d v=\oint_{\partial \Omega} s_{i}(\mathbf{x}, \tau) \delta u_{i}(\mathbf{x}) d a-\int_{\Omega} s_{i j}(\mathbf{x}, \tau) \delta u_{i},{ }_{j}(\mathbf{x}) d v+ \\
& +\int_{\Omega} \rho(\mathbf{x}) b_{i} \delta u_{i}(\mathbf{x}) d v, \\
& \frac{\mathrm{d}}{\mathrm{d} \tau} \int_{\Omega} \varepsilon(\mathbf{x}, \tau) \delta \theta(\mathbf{x}) \mathrm{dv}=\oint_{\partial \Omega} \mathrm{q}(\mathbf{x}, \tau) \delta \theta(\mathbf{x}) \mathrm{da}-\int_{\Omega} \mathrm{q}_{\mathrm{i}}(\mathbf{x}, \tau) \delta \theta,{ }_{\mathrm{i}}(\mathbf{x}) \mathrm{d} \mathbf{v}+ \\
& +\int_{\Omega}\left[\alpha(\mathbf{x}, \tau)+s_{\mathrm{ij}}(\mathbf{x}, \tau) \dot{\mathrm{u}}_{\mathrm{i}}, \mathrm{j}_{\mathrm{j}}(\mathbf{x}, \tau)\right] \delta \theta(\mathbf{x}) \mathrm{dv},
\end{aligned}
$$

where $\delta u_{i}, \delta \theta$ are sufficiently regular test functions. The constitutive equations will be assumed in the linearized form

$$
\begin{aligned}
\varepsilon(\mathbf{x}, \tau)= & \frac{1}{2} C_{i j k l}(x) u_{(i, j)}(x, \tau) u_{(k, l)}(x, \tau)+B_{i j}(x) u_{(i, j)}(x, \tau) \theta(x, \tau)+ \\
& +\frac{1}{2} c(x) \theta^{2}(\mathbf{x}, \tau), \\
s_{i j}(x, \tau)= & C_{i j k l}(x) u_{(i, j)}(x, \tau)+B_{i j}(x) \theta(x, \tau), \quad q_{i}(x, \tau)=K_{i j}(x) \theta,{ }_{j}(x, \tau),
\end{aligned}
$$

where the elastic modulae $\mathrm{C}_{\mathrm{ijk} \mid}(\cdot)$, the thermal conductivity modulae $\mathrm{K}_{\mathrm{ij}}(\cdot)$, the thermal expansion modulae $\mathrm{B}_{\mathrm{ij}}(\cdot)$ and the specific heat $\mathrm{c}(\cdot)$ are $\mathrm{V}$-periodic functions. Eqs (2) have to satisfy the known dissipation condition. 
If Eqs (1) hold for arbitrary regular test functions $\delta u_{i}, \delta \theta$ then Eqs (1), (2) are equivalent to the well known equations of the linear thermo-elastodynamics, which for composite materials have to be considered together with the continuity conditions $\left[\sigma_{i j}\right] n_{j}=0,\left[h_{i}\right] n_{i}=0$ on the interfaces between constituents. However, due to the highly oscillating (V-periodic) form of Eqs (2), the aforementioned equations do not constitute the proper analytical tool for investigations of composite bodies. In order to formulate macro-modelling assumptions leading from Eqs (1), (2) to the equations of the refined thermo-elastodynamics we have to introduce certain preliminary concepts.

\subsection{PRELIMINARY CONCEPTS}

The first preliminary concept we are to introduce is related to the expected form of disturbances in displacement and temperature fields caused by the inhomogeneity of the medium. To this end we shall assume that from the qualitative viewpoint these disturbances can be described by a sequence of $n$ linear independent functions $h^{\mathrm{a}}(\mathbf{x})$, $\mathbf{x} \in \mathbf{R}^{3}$, which are V-periodic, continuous, have piece wise continuous first derivatives $\mathrm{h}^{\mathrm{a}}{ }_{\mathrm{i}}$ suffering jump discontinuities across the interfaces between constituents and satisfy conditions: $\left\langle\mathrm{h}^{\mathrm{a}}\right\rangle=0,\left\langle\mathrm{~h}^{\mathrm{a}},{ }_{\mathrm{i}}\right\rangle=0,\left\langle\mathrm{\rho h}^{\mathrm{a}}\right\rangle=\left\langle\alpha \mathrm{h}^{\mathrm{a}}\right\rangle=\left\langle\mathrm{ch}^{\mathrm{a}}\right\rangle=\left\langle\mathrm{B}_{\mathrm{ij}} \mathrm{h}^{\mathrm{a}}\right\rangle=0$. Moreover, we assume that $\mathrm{h}^{\mathrm{a}}(\mathbf{x}) \in Q(l)$, where $l \equiv \max l_{\mathrm{i}}$ is the microstructure length parameter, and that the values $h^{\mathrm{a}}{ }_{i}(\mathbf{x})$ of the derivatives of $h^{\mathrm{a}}$ are independent of $l$. Functions $h^{\mathrm{a}}(\cdot)$ are called micro-shape functions; their specification depends on the material structure of the representative volume element $\mathrm{V}$ of the periodic composite and can be also related to a certain discretization procedure of $\mathrm{V}$; for particulars the reader is referred to [3-5].

Let $\lambda$ be a small macro-accuracy parameter related to the calculations of a certain real-valued function $F(\cdot)$ defined on $\Omega$ (F can also depend on the time coordinate $\tau$ ). Function $F$ will be called $V$-macro function if for every $\mathbf{x}, \mathbf{y} \in \Omega$ such that $\mathbf{x}-\mathbf{y} \in V$ condition $|F(x)-F(y)|<\lambda$ holds. If the condition of this form also holds for all derivatives of $\mathrm{F}$ then $\mathrm{F}$ will be referred to as the regular V-macro function. For any integrable $\mathrm{V}$-periodic function $\mathrm{f}(\cdot)$, micro-shape function $\mathrm{h}^{\mathrm{a}}(\cdot)$ and regular $\mathrm{V}$-macro function $F(\cdot)$, we obtain 


$$
\begin{aligned}
& \int_{\Omega} f(x) F(x) d v=<f>\int_{\Omega} F(x) d v+Q(\lambda), \\
& \left(h^{a}(x) F(x)\right),{ }_{i}=h^{a}{ }_{i}(x) F(x)+Q(\lambda),
\end{aligned}
$$

The concept of a regular V-macro function is strictly related to the macroscopic description of the behaviour of a composite in which the oscillations of functions within every single periodicity cell can be neglected, [5].

\subsection{MACRO-MODELLING ASSUMPTIONS}

The passage from Eqs (1), (2) of micromechanics to the proposed macro-model of a composite will be based on the following modelling assumptions.

Micro-Macro Localization Hypothesis. The displacement and temperature fields in the micro-periodic body can be expected in the form

$$
\begin{aligned}
& \mathbf{u}_{\mathrm{i}}(\mathbf{x}, \tau)=U_{\mathrm{i}}(\mathbf{x}, \tau)+\mathrm{h}^{\mathrm{a}}(\mathbf{x}) \mathrm{V}_{\mathrm{i}}^{\mathrm{a}}(\mathbf{x}, \tau), \\
& \theta(\mathbf{x}, \tau)=\Theta(\mathbf{x}, \tau)+\mathrm{h}^{\mathrm{a}}(\mathbf{x}) \Phi^{\mathrm{a}}(\mathbf{x}, \tau), \quad \mathbf{x} \in \Omega,
\end{aligned}
$$

where $\mathrm{U}_{\mathrm{i}}(\cdot, \tau), \mathrm{V}_{i}^{\mathrm{a}}(\cdot, \tau), \Theta(\cdot, \tau), \Phi^{\mathrm{a}}(\cdot, \tau)$ are arbitrary regular $\mathrm{V}$-macro functions and $\mathrm{h}^{\mathrm{a}}(\cdot)$ are micro-shape functions, postulated in every problem under consideration.

Fields $U_{i}$ and $\Theta$ will be called macro-displacement and macro-temperature field, respectively. Fields $V_{i}^{a}, \Phi^{a}$ are referred to as correctors and describe, from the quantitative point of view, the possible disturbances in displacements and a temperature caused by the micro-periodic inhomogeneous structure of a composite.

Macro-Balance Assumption. The balance equations (1) are assumed to hold for $\delta \mathrm{u}_{\mathrm{i}}=$ $=\delta \mathrm{U}_{\mathrm{i}}+\mathrm{h}^{\mathrm{a}} \delta \mathrm{V}_{\mathrm{i}}^{\mathrm{a}}, \delta \theta=\delta \Theta+\mathrm{h}^{\mathrm{a}} \delta \Phi^{\mathrm{a}}$, where $\delta \mathrm{U}_{\mathrm{i}}, \delta \mathrm{V}_{\mathrm{i}}^{\mathrm{a}}, \delta \Theta, \delta \Phi^{\mathrm{a}}$ are arbitrary linear independent regular $\mathrm{V}$-macro functions.

Macro-Modelling Approximation. In the balance equations (1) terms $\theta(\lambda)$ in integrals over $\Omega$ and terms $\theta(I)$ in integrals over $\partial \Omega$ can be neglected. 


\section{Refined theory}

Substituting the right-hand sides of Eqs (2) into Eqs (1) and using the aforementioned macro-modelling assumptions (we apply formulae (3)), after some manipulations and introducing the following $V$-macro fields

$$
\begin{aligned}
& \mathrm{S}_{\mathrm{ij}}=<\mathrm{C}_{\mathrm{ijkl}}>\mathrm{U}_{\mathrm{k}, 1}+<\mathrm{C}_{\mathrm{ijkl}} \mathrm{h}^{\mathrm{a}}{ }_{\mathrm{k}}>\mathrm{V}_{\mathrm{l}}^{\mathrm{a}}+<\mathrm{B}_{\mathrm{ij}}>\Theta+<\mathrm{B}_{\mathrm{ij}} \mathrm{h}^{\mathrm{b}}>\Phi^{\mathrm{b}}, \\
& H_{i}^{a}=<C_{i j k l} h^{a},{ }_{j}>U_{k, l}+<C_{i j k l} h^{a},_{j} h^{b}, l>V_{k}^{b}+<B_{i j} h^{a}, j>\Theta+ \\
& +<\mathrm{B}_{\mathrm{ij}} \mathrm{h}^{\mathrm{a}}, \mathrm{j} \mathrm{h}^{\mathrm{b}}>\Phi^{\mathrm{b}}, \\
& \mathrm{Q}_{\mathrm{i}}=<\mathrm{K}_{\mathrm{ij}}>\Theta_{, \mathrm{j}}+<\mathrm{K}_{\mathrm{ij}} \mathrm{h}^{\mathrm{b}},{ }_{\mathrm{j}}>\Phi^{\mathrm{b}} \text {, } \\
& G^{a}=<K_{i j} h^{a}, j>\Theta_{, i}+<K_{i j} h^{a}{ }_{i} h^{b}{ }_{, j}>\Phi^{b} \text {, }
\end{aligned}
$$

we obtain

$$
\begin{aligned}
& <\rho>\ddot{\mathrm{U}}-\mathrm{S}_{\mathrm{ij}, \mathrm{j}}=<\rho>\mathrm{b}_{\mathrm{i}}, \\
& <\rho \mathrm{h}^{\mathrm{a}} \mathrm{h}^{\mathrm{b}}>\ddot{\mathrm{V}}_{\mathrm{i}}^{\mathrm{b}}+\mathrm{H}_{\mathrm{i}}^{\mathrm{a}}=0, \\
& <\mathrm{c}>\dot{\Theta}-\mathrm{Q}_{\mathrm{i}, \mathrm{i}}+<\mathrm{B}_{\mathrm{ij}}>\dot{\mathrm{U}}_{\mathrm{i}, \mathrm{j}}+<\mathrm{B}_{\mathrm{ij}} \mathrm{h}^{\mathrm{b}},{ }_{\mathrm{j}}>\dot{\mathrm{V}}_{\mathrm{i}}^{\mathrm{b}}=<\alpha>, \\
& <\mathrm{ch}^{\mathrm{a}} \mathrm{h}^{\mathrm{b}}>\dot{\Phi}^{\mathrm{b}}+<\mathrm{B}_{\mathrm{ij}} \mathrm{h}^{\mathrm{b}},{ }_{\mathrm{j}} \mathrm{h}^{\mathrm{a}}>\dot{\mathrm{V}}_{\mathrm{i}}^{\mathrm{b}}+\mathrm{G}^{\mathrm{a}}=0,
\end{aligned}
$$

and $S_{i j} n_{j}=s_{i}, Q_{i} n_{i}=q$ on $\partial \Omega$. Substituting the right-hand sides of Eqs (5) into Eqs (6) we arrive at the system of $4+4 n$ equations for macro-displacements $U_{i}$, macro-temperature $\Theta$ and correctors $V_{i}^{a}, \Phi^{a}$. These equations have constant coefficients and hence, represent a certain macro-model of the periodic body under consideration. The 
underlined constants in Eqs (5), (6) depend on the microstructure length parameter $l$ and describe the effect of the microstructure on the behaviour of the composite. Hence, Eqs (5), (6) represent the refined macro-thermoelastodynamics of composite materials and will be called macro-constitutive equations and local macro-balance equations, respectively. It has to be emphasized that the equations for correctors (the second and the last from Eqs(6)) are ordinary differential equations and hence, the correctors play a role of certain internal dynamical variables, i.e., they do not enter boundary conditions. For a homogeneous body from Eqs (5), (6) we obtain $\mathrm{V}_{i}^{\mathrm{a}}=0, \Phi^{\mathrm{a}}=0$, provided that initial values of $V_{i}^{a}, \dot{V}_{i}^{a}$ and $\Phi^{a}$ are equal to zero. Hence, we see that correctors describe the effect of inhomogeneity on the macro-behaviour of the body.

\section{Effective Modulus Theory}

Scaling the microstructure down in Eqs (5), (6) by means of $l \rightarrow 0$, we arrive at a certain asymptotic theory; in this case the underlined terms are equal to zero and we arrive at conditions $\mathrm{H}_{\mathbf{i}}^{\mathrm{a}}=0, \mathrm{G}^{\mathrm{a}}=0$ representing the systems of linear algebraic equations for the correctors $\mathrm{V}_{\mathrm{i}}^{\mathrm{a}}, \Phi^{\mathrm{a}}$. Hence, eliminating correctors from Eqs (5), (6) we obtain equations of a certain special effective modulus theory, given by

$$
\begin{aligned}
& <\rho>\ddot{U}_{i}-S_{i j}, j=<\rho>b_{i}, \quad c^{\text {eff }} \dot{\Theta}-Q_{i, i}+B_{i j}^{\text {eff }} \dot{U}_{i, j}=<\alpha>, \\
& S_{i j}=C_{i j k J}^{\text {eff }} U_{k, l}+B_{i j}^{\text {eff }} \Theta, \quad Q_{i}=K_{i j}^{\text {eff }} \Theta, j \text {. }
\end{aligned}
$$

The constant coefficients in Eqs (7) are termed effective modulae and defined by:

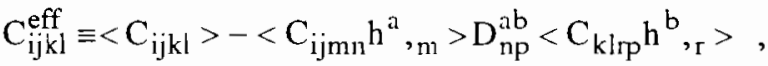

$$
\begin{aligned}
& \mathrm{B}_{\mathrm{ij}}^{\text {eff }} \equiv<\mathrm{B}_{\mathrm{ij}}>-<\mathrm{B}_{\mathrm{kl}} \mathrm{h}^{\mathrm{a}}{ }_{, 1}>\mathrm{D}_{\mathrm{kp}}^{\mathrm{ab}}<\mathrm{C}_{\mathrm{prij}} \mathrm{h}^{\mathrm{b}}{ }_{{ }_{\mathrm{r}}}>\text {, } \\
& \mathrm{K}_{\mathrm{ij}}^{\text {eff }} \equiv<\mathrm{K}_{\mathrm{ij}}>-<\mathrm{K}_{\mathrm{ik}} \mathrm{h}^{\mathrm{a}}{ }_{, \mathrm{k}}>\mathrm{D}^{\mathrm{ab}}<\mathrm{K}_{\mathrm{jl}} \mathrm{h}^{\mathrm{b}}{ }_{, 1}>\text {, } \\
& c^{\text {eff }} \equiv<c>-<B_{i j} h^{a},{ }_{j}>D_{i k}^{a b}<B_{k !} h^{b},{ }_{l}>\text {, }
\end{aligned}
$$


where $D_{i k}^{a b}$ and $D^{a b}$ represent linear transformations inverse to those given by $<\mathrm{C}_{\mathrm{ijk} l} \mathrm{~h}^{\mathrm{a}},{ }_{\mathrm{j}} \mathrm{h}^{\mathrm{b}}, \mathrm{p}$ and $\left\langle\mathrm{K}_{\mathrm{ij}} \mathrm{h}^{\mathrm{a}},{ }_{\mathrm{i}} \mathrm{h}^{\mathrm{b}},{ }_{\mathrm{j}}\right\rangle$, respectively. The aforementioned results have been derived independently in [3], without any reference to the refined theory.

\section{Example of Application}

Let us consider a laminated body made of two orthotropic constituents. In this case we introduce one micro-shape function $h\left(x_{1}\right)$ (periodic in a direction $x_{1}$ normal to the lamina interfaces, cf. [1] ), denoting by $\mathrm{V}_{\mathrm{k}}, \Phi$ the pertinent correctors related to $\mathrm{h}\left(\mathrm{x}_{1}\right)$. For the sake of simplicity let us neglect the body forces $b_{i}$ and heat supply $\alpha$. The aim of this example is to show a difference between results obtained from the refined theory and those derived from the effective modulus theory. To this end we shall consider the homogeneous boundary conditions for the macro-displacements and macro-temperature: $U_{i}=0, Q_{i} n_{i}=0$ on $\partial \Omega$, homogeneous initial conditions for the macro-displacements and correctors: $U_{i}=0, \dot{U}_{i}=0, V_{i}=0, \dot{V}_{i}=0, \Phi=0$ at $\tau=0$ and the initial condition for the macro-temperature in the form: $\Theta=\Theta_{0}$ at $\tau=0, \Theta_{0}=$ const. Then in the framework of the refined theory we obtain $U_{i}=0, V_{2}=V_{3}=\Phi=0$ for every $\tau>0, \mathbf{x} \in \Omega$, and

$$
\begin{aligned}
& \Theta=\Theta_{0} \mathrm{~K}\left(1-\frac{\left\langle\mathrm{B}_{11} \mathrm{~h}_{, 1}\right\rangle^{2}}{\langle\mathrm{c}\rangle\left\langle\mathrm{C}_{1111}\left(\mathrm{~h}_{1,}\right)^{2}\right\rangle} \cos \omega \tau\right), \\
& \mathrm{V}_{1}=-\Theta_{0} \mathrm{~K} \frac{\left\langle\mathrm{B}_{11} \mathrm{~h}_{, 1}\right\rangle}{\left.<\mathrm{C}_{1111}\left(\mathrm{~h}_{, 1}\right)^{2}\right\rangle}(1-\cos \omega \tau),
\end{aligned}
$$

where

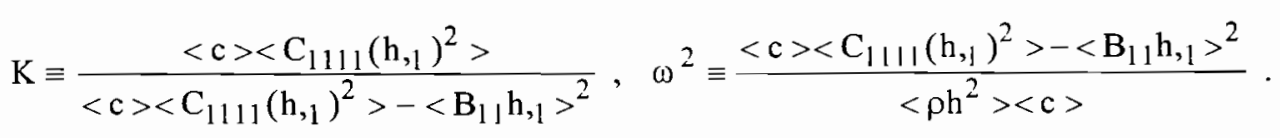

At the same time, the effective modulus theory yields the constant values of $\Theta$ and $V_{1}$ for every $\tau \geq 0$ : 


$$
\Theta=\Theta_{0}, \quad V_{1}=-\Theta_{0} \frac{\left\langle B_{1 !} h_{1}\right\rangle}{\left.<C_{1111}\left(h_{, 1}\right)^{2}\right\rangle}
$$

From Eqs (8) it follows that the inhomogeneity of the medium and the coupling between temperature and deformations produce highly oscillating character of the macro-temperature field; this fact is not described by the effective modulus theory leading to (9). Thus we conclude that in investigations of non-stationary processes in thermo-elastic composites, the refined macro-elastodynamics has to be used instead of the effective modulus theory.

Acknowledgment. This research work was supported by KBN, Warsaw, under grant 333109203.

\section{References}

1. Bensoussan, A., Lions, J. L., Papanicolaou, G. (1980), Asymptotic Analysis of Periodic Structures, Nortli-Holland Publ. Comp., Amsterdam.

2. Baclivalov, N. S., Panasenko, G. P. (1984), Process Averaging in Periodic Media [in Russian], Nauka, Moskva.

3. Matysiak, S., Woźniak, Cz. (1987) Micromorphic effects in a modelling of periodic multilayered elastic composites, Int. J. of Engng. Sci. 25, 549-559.

4. Woźniak, Cz. (1989) On the modelling of thermo-unelastic periodic composites, Acta Mechamica 80, 81-94.

5. Woźniak, Cz. (1993) Refined macro-dynamics of periodic structures, Arch. Mech. 45, 295-304.

6. Konieczny, S., Wożniak, Cz. Woźniak, M. (1993) A note on dynamic modelling of periodic composites, Arch. Mech. 45, 779-783.

7. Woźnak, Cz. (1993) Micro-macro dynamics of periodic material structures, in $\Upsilon$. Moan et al. (eds.), Structural Dynamics, Proceedings of Eurodyn '93, A. A. Balkema, Rotterdam, 573-575. 